\title{
Review
}

\section{Using Alzheimer's disease as a model for genetic risk disclosure: implications for personal genomics}

Roberts JS, Christensen KD, Green RC. Using Alzheimer's disease as a model for genetic risk disclosure: implications for personal genomics. Clin Genet 2011: 80: 407-414. (C) John Wiley \& Sons A/S, 2011

Susceptibility testing for common, complex adult-onset diseases is projected to become more commonplace as the rapid pace of genomic discoveries continues, and evidence regarding the potential benefits and harms of such testing is needed to inform medical practice and health policy. Apolipoprotein E (APOE) testing for risk of Alzheimer's disease (AD) provides a paradigm in which to examine the process and impact of disclosing genetic susceptibility for a prevalent, severe and incurable neurological condition. This review summarizes findings from a series of multi-site randomized clinical trials examining psychological and behavioral responses to various methods of genetic risk assessment for $\mathrm{AD}$ using $A P O E$ disclosure. We discuss challenges involved in disease risk estimation and communication and the extent to which participants comprehend and perceive utility in their genetic risk information. Findings on the psychological impact of test results are presented (e.g. distress), along with data on participants' health behavior and insurance purchasing responses (e.g. long-term care). Finally, we report comparisons of the safety and efficacy of intensive genetic counseling approaches to briefer models that emphasize streamlined processes and educational materials. The implications of these findings for the emerging field of personal genomics are discussed, with directions identified for future research.

\section{Conflict of interest}

The authors report no conflicts related to the work presented herein.

\section{JS Roberts ${ }^{a}$, KD Christensen ${ }^{a}$ and RC Green ${ }^{\mathrm{b}}$}

aDepartment of Health Behavior and Health Education, University of Michigan School of Public Health, Ann Arbor, MI,

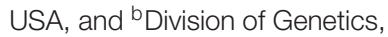

Department of Medicine, Brigham and Women's Hospital, Harvard Medical School, Boston, MA, USA

Key words: Alzheimer disease APOE - genetic testing - risk communication

Corresponding author: J. Scott Roberts, $\mathrm{PhD}$,

Department of Health Behavior and Health Education, University of Michigan School of Public Health, 1415 Washington Heights, Ann Arbor, Ml 48109, USA.

Tel.: +1 734 936-9854; fax: +1 7347637379 ; e-mail: jscottr@umich.edu

Received 13 April 2011, revised and accepted for publication 20 June 2011

\section{Background}

Genetic susceptibility testing for common, complex diseases

Genomic discoveries are transforming medical science, in part by providing new methods to predict the occurrence (1) or progression (2) of diseases that have a genetic basis. Because of their public health significance, there has been great interest in the identification of susceptibility genes for common, complex conditions in particular. Genetic susceptibility testing for common disease provides information about risk that is, by definition, influenced by a complex (and not always understood) interplay among genes, environment and behavior. This type of information lacks the degree of certainty of highly penetrant Mendelian variants, where the presence or absence of specific mutations is more clearly associated with the future manifestation (or not) of a given disease. Because of their limitations, there is concern that many new tests are prematurely moving into the clinical arena and the directto-consumer (DTC) marketplace (3, 4). Skeptics 


\section{Roberts et al.}

express concerns over the limited predictive value of genetic susceptibility testing, along with potential harms including psychological distress, misunderstanding of risk information, and insurance or employment bias $(5,6)$. On the other hand, personalized disease management and pharmaceutical regimens tailored to individuals' genotypes represent promising applications of genomics research $(7,8)$. Experts forecast that genomic discoveries will increase options for prevention and treatment of common, complex health conditions such as diabetes, heart disease, and cancer (9). Some contend that personalized genomic risk information can help prompt individuals to make lifestyle changes to avoid or reduce their disease risk (10).

Although there is much debate over the likelihood and extent of benefits to be derived from genetic susceptibility testing, it appears clear that the use of this modality will increase in the coming years. Such markers can often be measured with relative ease once identified and the initiative of motivated individuals and the power of market forces may make it difficult to limit or prevent the widespread use of susceptibility genotyping in the future. Our responsibility as experts may be to understand how to use them wisely and to articulate whether and under what circumstances they should be used. Clinical research, as opposed to ideologically based speculation, would seem to be the best guide of policy and practice in this arena. Given the vast number of genetic markers and conditions to consider, one research strategy is to select 'sentinel' cases where genetic susceptibility testing for common, adult-onset conditions is available. This has been our approach, as we have used genetic susceptibility testing for Alzheimer's disease as a paradigm in which to examine the process and impact of disclosing genetic risk information to asymptomatic adults.

\section{Genetic testing for Alzheimer's disease}

Alzheimer's disease (AD) is the most common type of dementia in the United States, with a prevalence expected to increase dramatically in coming decades (11). The genetics of $\mathrm{AD}$ have been comprehensively summarized elsewhere. Briefly, mutations in each of three genes (APP, PS1 and $P S 2)$ are associated with early onset, autosomal dominantly inherited forms of AD. Genetic testing already occurs for these rare familial forms of $\mathrm{AD}$, with counseling procedures based on the Huntington's disease testing model (12). However, these mutations account for a very small proportion of $\mathrm{AD}$ cases. Much more common is a variant of the susceptibility polymorphism Apolipoprotein $\mathrm{E}(A P O E)$, a plasma protein involved in cholesterol transport. $A P O E$ has three common alleles $(\varepsilon 2, \varepsilon 3$ or $\varepsilon 4)$. The $\varepsilon 4$ allele is a robust risk factor for sporadic and late-onset familial $\mathrm{AD}$, with the degree of risk varying depending upon whether the individual carries one or two $\varepsilon 4$ alleles (13). Discoveries of new susceptibility genes over the past decade $(14,15)$ have increased our knowledge of potential genetic determinants of $\mathrm{AD}$, but none of these has been as frequently replicated nor has as notable a risk effect as $A P O E$.

In the mid- to late 1990s, several expert consensus statements cautioned against the clinical use of predictive testing for AD using $A P O E$, largely because of the fact that information about the future risk of developing $\mathrm{AD}$ does not change clinical care given the limited treatment and prevention options for the disease (16-19). In addition, possession of an $\varepsilon 4$ allele is neither necessary nor sufficient to cause AD. However, each of the aforementioned statements concluded along these lines: 'More research is needed on how individuals and families understand complex probabilistic genetic information and on the implications of living one's life "at risk" for developing AD' (19).

Research on genetic susceptibility testing for AD may be useful for understanding how individuals will respond to susceptibility testing for common, complex diseases in general. Genetic risk factors now being identified for other complex diseases via genome-wide association studies are similar to $A P O E$ in which (i) they are more prevalent in the general population than rare Mendelian variants, (ii) their positive predictive value is relatively low, and (iii) testing for these variants is now being marketed to the public through commercial firms. Although its lack of proven prevention options sets AD apart from modifiable conditions such as heart disease and diabetes, there is growing scientific evidence that environment, lifestyles, and social factors may influence risk of $\mathrm{AD}$ and related dementias $(11,20)$. The majority of the public believes that lifestyle, diet, and mental inactivity contribute to AD risk even while they endorse genetics as the most important risk factor for AD (21). Furthermore, individuals who seek genetic susceptibility testing for $\mathrm{AD}$ commonly cite disease risk reduction as a prime motivator (22). In sum, laypersons appear to view $\mathrm{AD}$ as more 'modifiable' than current scientific evidence suggests. In the next section, we describe a series of clinical trials designed to examine the psychological and behavioral impact of providing genetic susceptibility testing for $\mathrm{AD}$. 
Alzheimer's disease as a model for genetic risk disclosure

Table 1. Overview of REVEAL clinical trials

\begin{tabular}{|c|c|c|c|c|}
\hline Trial & Dates & Site locations & Study sample & Main question(s) \\
\hline REVEAL I & $2000-2003$ & $\begin{array}{l}\text { Boston } \\
\text { Cleveland } \\
\text { New York City }\end{array}$ & $\begin{array}{l}162 \text { Adult children of } \\
\text { people with } A D\end{array}$ & $\begin{array}{l}\text { What is the psychological impact of } \\
\text { disclosure of genetic risk for AD? }\end{array}$ \\
\hline REVEAL II & 2003-2006 & $\begin{array}{l}\text { Boston } \\
\text { Cleveland } \\
\text { New York City } \\
\text { Washington, DC }\end{array}$ & $\begin{array}{l}280 \text { First-degree } \\
\text { relatives of people } \\
\text { with } A D\end{array}$ & $\begin{array}{l}\text { Can genetic risk for AD be } \\
\text { disclosed safely and effectively } \\
\text { using a condensed protocol? }\end{array}$ \\
\hline REVEAL III & 2006-2009 & $\begin{array}{l}\text { Boston } \\
\text { Cleveland } \\
\text { Washington } \\
\text { Ann Arbor, DC }\end{array}$ & $\begin{array}{l}257 \text { Adults with and } \\
\text { without immediate } \\
\text { AD family history }\end{array}$ & $\begin{array}{l}\text { What is the impact of disclosure of } \\
\text { pleiotropic disease risks } \\
\text { associated with APOE? Can } \\
\text { results be disclosed safely and } \\
\text { effectively via phone? }\end{array}$ \\
\hline REVEAL IV & 2010-present & $\begin{array}{l}\text { Boston } \\
\text { Philadelphia } \\
\text { Washington } \\
\text { Ann Arbor, DC }\end{array}$ & $\begin{array}{l}\text { Persons with amnestic } \\
\mathrm{MCl} \text { and their study } \\
\text { partners }\end{array}$ & $\begin{array}{l}\text { What is the impact of disclosing } \\
\text { APOE to a population at } \\
\text { imminent risk of AD? }\end{array}$ \\
\hline
\end{tabular}

AD, Alzheimer's disease; APOE, apolipoprotein E; REVEAL, Risk Evaluation and Education for Alzheimer's Disease.

\section{Disclosing genetic risk for AD: the REVEAL Study}

Overview

The Risk Evaluation and Education for Alzheimer's Disease (REVEAL) Study is a series of multisite randomized clinical trials that examines the impact of $A P O E$ genetic susceptibility testing on asymptomatic individuals (Table 1). An interdisciplinary team of clinicians, geneticists, genetic counselors, health psychologists, ethicists and policy scholars created protocols to evaluate the impact of $A P O E$ disclosure for evaluating $\mathrm{AD}$ risk. The first REVEAL Study trial compared a genetic risk assessment program that incorporated $A P O E$ genotype disclosure against a more general AD risk assessment. The second trial built on the first by expanding the participant profile to include more African Americans and to test a condensed educational and counseling protocol against a more traditional model based on genetic testing for cancer susceptibility. The third trial explored the impact of disclosing that the $\varepsilon 4$ allele of $A P O E$ is associated with coronary artery disease in addition to $\mathrm{AD}$ and also tested a telephone disclosure protocol against in-person disclosure. The fourth trial, just underway, is exploring the impact of an AD genetic risk assessment for individuals already with mild cognitive impairment (MCI).

In each trial, participants complete a baseline assessment and then receive pre-test education about study requirements and the risk information that will be disclosed. Following a blood draw for genotyping purposes, participants receive personalized $\mathrm{AD}$ risk estimates through age 85 (range:
6-77\%) depending on gender, self-identified ethnicity (REVEAL II and III, only), family history of $\mathrm{AD}$ and, for most participants, $A P O E$ genotype. These risks were derived from a longstanding multi-site program of genetic epidemiology research (23). Participants are followed 1 year to assess the impact of the risk assessment on outcomes described below.

\section{Risk estimation}

As is the case with other complex diseases, AD etiology poses numerous challenges for risk estimation. Although individual studies have suggested scores of potential risk and protective factors for $\mathrm{AD}$, many have not been confirmed in prospective studies and it is unclear whether and to what extent these risk factors are additive or interactive. The risk estimates developed in REVEAL were therefore based only on well-established AD risk factors including age, gender, family history, and $A P O E$ genotype using (i) sex- and family history-specific incidence curves based on a large-scale epidemiological study (24) and (ii) $A P O E$ genotype-specific odds ratio estimates from a meta-analysis of data over 50 studies worldwide (25). However, our estimates did not take into account other potential risk factors for the disease, including other genes, gene-gene interactions, gene-environment interactions, environmental exposures, and other demographics factors. Participants were notified of these limitations during pre-test education and when disclosed their risk of AD.

Another challenge was the issue of differing risks across racial and ethnic groups. Several 


\section{Roberts et al.}

epidemiological studies have suggested that African Americans are at higher risk than Whites, but the underlying reasons for this disparity are not fully understood. Whether and how to disclose ethnicity-specific risk estimates raised both scientific and ethical dilemmas given the troubled history of genetic research with African Americans (26). Guided by both expert consensus and focus group data from African American community members, risk models specific to ethnicity, gender, and $A P O E$ genotype were subsequently developed for the second REVEAL trial such that African Americans and Whites received differing risk estimates (Table 2) (27). The experience of risk estimation in REVEAL offers lessons for how to address the ambiguity and ethical tensions inherent in risk disclosure for a complex disease whose etiology is not well-understood.

\section{Interest in testing}

The REVEAL Study has shed light on those who might express interest in genetic susceptibility testing for common complex disease. Among participants in the first REVEAL trial who had been recruited from research registries, those who were under the age of 60 and those who were college educated were more likely to progress from initial contact to randomization. Among participants who self-referred to the study after hearing about it in a memory assessment clinic, the media, or in a public presentation, the average education level was more than a college degree and $79 \%$ were female (28). Although some of these trends may be driven by the characteristics of Alzheimer's disease rather than the characteristics of testing (e.g. the need to plan for $\mathrm{AD}$ in middle age and gender disparities in AD caregiving), differences by gender and education have also been seen to a lesser

Table 2. Lifetime risk estimates (through age 85) for firstdegree relatives of people with $\mathrm{AD}$, stratified by gender, $A P O E$ genotype, and ethnic group

\begin{tabular}{lcccc}
\hline Genotype & $\begin{array}{c}\text { White } \\
\text { men (\%) }\end{array}$ & $\begin{array}{c}\text { White } \\
\text { women (\%) }\end{array}$ & $\begin{array}{c}\text { AA } \\
\text { men (\%) }\end{array}$ & $\begin{array}{c}\text { AA } \\
\text { women (\%) }\end{array}$ \\
\hline$\varepsilon 2 / \varepsilon 3^{a}$ & 13 & 19 & 33 & 36 \\
$\varepsilon 3 / \varepsilon 3$ & 18 & 29 & 41 & 49 \\
$\varepsilon 2 / \varepsilon 4$ & 25 & 49 & 48 & 69 \\
$\varepsilon 3 / \varepsilon 4$ & 29 & 52 & 56 & 73 \\
$\varepsilon 4 / \varepsilon 4$ & 56 & 57 & 77 & 74 \\
\hline
\end{tabular}

$\mathrm{AA}$, African American; AD, Alzheimer's disease; APOE, apolipoprotein $\mathrm{E}$.

$a_{\varepsilon 2 / \varepsilon 2}$ estimates are not provided because there was not sufficient prevalence of this genotype in our epidemiological studies to provide robust risk estimates. extent in other studies of genetic susceptibility testing $(29,30)$.

\section{Perceived utility of testing}

As mentioned above, genetic testing in clinical practice is typically judged on whether or not it can inform medical care options. However, our findings showed that participants had numerous reasons for seeking testing that would not be classified under usual definitions of clinical utility. For example, the vast majority of participants endorsed reasons for seeking testing that included the following: arranging personal affairs, informing decisions about long-term care insurance, preparing the family for the possibility of illness, and emotional relief if found to be at lower risk (31). Of note, here are the perceived benefits of genetic testing for psychological well-being and advanced planning; many participants believed that information would be helpful even in the absence of proven medical care options to reduce their AD risk.

\section{Risk recall and perceptions}

Our experience also showed the challenges in conveying genetic risk information for a complex disease. Informed by the health risk communication literature, our counseling and education materials included the following: take-home written materials to reinforce information presented (32), strategies for coping with risk and resources for further information, and graphical representations of risk information to guide in-person counseling (33). For example, we used visual aids including risk curves specific to gender, ethnicity, family history and $A P O E$ genotype that conveyed risk of $\mathrm{AD}$ through age 85 and in comparison to reference groups including the general population (34). These curves also showed risk over time, reinforcing the importance of the interactive effect between age and APOE (Fig. 1). Yet even despite these efforts and a well-educated set of participants, many could not recall their lifetime risk information at a 6-week follow-up. However, the vast majority knew their $A P O E$ status, suggesting that genotype is more memorable to participants than lifetime risk and reinforcing the notion that gistlevel health information is often retained instead of specific numeric estimates (35).

Results also suggested that genotype information has an outsized influence on risk perceptions, even when offered within a multi-factorial risk assessment. For example, we compared women with $\varepsilon 4$-negative test results to a control group of women who received an identical lifetime risk 


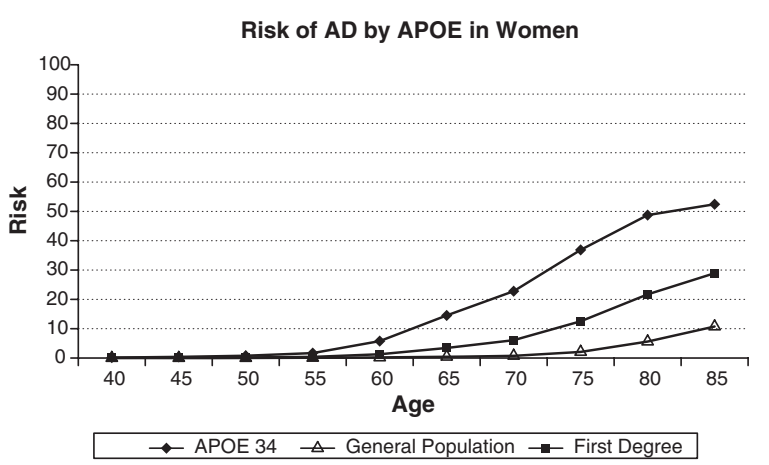

Fig. 1. Sample risk curve presented to REVEAL participants. REVEAL, Risk Evaluation and Education for Alzheimer's Disease.

estimate but who were not disclosed their $A P O E$ status. Although both groups received the same 'take-home' message about lifetime risk of $\mathrm{AD}$ (i.e. $29 \%$ probability), the $\varepsilon 4$-negative women perceived their risk as lower, reported testing as having a more positive impact, endorsed less strongly the belief that they might develop AD, and reported a greater reduction in anxiety about $\mathrm{AD}$ (Fig. 2) (36). Ongoing analyses in REVEAL are continuing to explore the extent to which 'negative' genetic test results contribute to a potentially false sense of reassurance about disease risk.

Data also suggest that calculated risk estimates are often not taken at face value. Approximately half of the participants in the second REVEAL trial who could accurately recall their numerical risk estimates asserted that their lifetime risk for $\mathrm{AD}$ was either lower or higher than what was calculated (37). Some participants appeared to be 'anchored' to their initial, pre-test AD risk perceptions. Others may have adjusted for personal risk or protective factors not accounted for in our risk estimates.

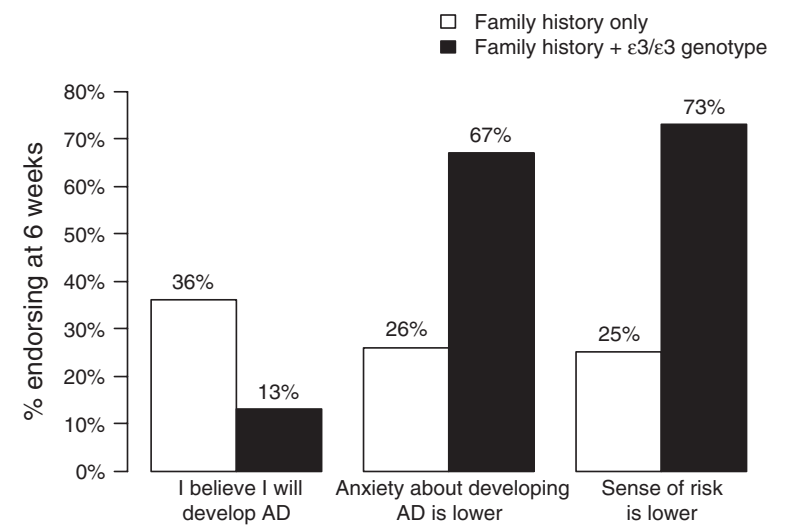

Fig. 2. Proportion of participants receiving identical $29 \%$ numerical risk estimates that endorsed perceived risk survey items, stratified by risk disclosure group.
Psychological impact of APOE disclosure

A prominent concern about genetic testing for $\mathrm{AD}$ is the potential of psychological harm when disclosing risk information for a severe, incurable disorder (18). In our first trial, clinical symptoms of anxiety, depression and test-related distress were assessed up to 1 year following disclosure using validated self-reported measures, including the Beck Anxiety Inventory (38), Center for Epidemiologic Studies-Depression Scale (39), and the Impact of Events Scale (40), respectively. Results showed no difference in changes in the timeaveraged measures between the intervention (risk assessment with $A P O E$ genotype disclosure) and control (risk assessment without APOE disclosure) arms. Secondary comparisons between those receiving $\varepsilon 4$-positive results and controls also found no significant differences. Results suggest that $A P O E$ genotype disclosure under carefully controlled circumstances to adult children of persons with AD did not pose significant psychological risks, even for those who learned they were $\varepsilon 4$-positive (41). These results are largely consistent with studies of the impact of genetic testing for other adult-onset disorders such as Huntington's disease and hereditary cancer syndromes; this research suggests that (i) baseline psychological functioning is a better predictor of post-test response than the actual test result itself and (ii) test-specific distress, while sometimes significant, is usually transient if patients are provided proper post-test counseling $(42,43)$. It should be pointed out, however, that these results may not generalize to current modes of $A P O E$ disclosure that are now occurring via DTC genetic testing companies. The latter model not only lacks in-person counseling but also discloses $A P O E$ information simultaneously with risks for numerous other conditions. This format would seemingly raise the chances that $\varepsilon 4$-positive results could come 'out of the blue' and thereby prove more psychologically distressing than as observed in our studies.

\section{Behavioral impact of disclosure}

Genetic risk information alone is typically insufficient to engender complex behavior changes such as smoking cessation and modification of dietary and exercise habits $(42,44)$. However, some studies suggest that genetic risk information may enhance patient preferences for biological interventions (e.g. medications) over health behavior changes (e.g. lifestyle changes) (45-47). Indeed, in the first two REVEAL trials, the most common health behavior change reported by participants 


\section{Roberts et al.}

was the addition of vitamins or nutritional supplements (e.g. vitamin E) (48). This finding may suggest a need to scrutinize emerging commercial services that are using genetic test results to market nutriceuticals of unproven benefit.

Another domain of interest was purchasing of long-term care (LTC) insurance. LTC insurance is relevant because $\mathrm{AD}$ often results in nursing home placement and lengthy inpatient stays. In our first trial, $\varepsilon 4$-positive participants were approximately four times more likely than controls to report LTC insurance changes during the 1-year followup (Fig. 3) (49), a finding that was replicated in our second trial (50). If $A P O E$ testing is utilized by a significant number of consumers to inform their LTC insurance purchasing, then insurers may be within their rights to address this adverse selection by increasing premiums or denying coverage based on $A P O E$ results. Policymakers will then have to decide whether to expand the Genetic Information Non-discrimination Act to address not only health insurance, but also other domains including LTC.

\section{Study limitations}

REVEAL findings should be interpreted with several study limitations in mind. Treatment and prevention options for $\mathrm{AD}$ are very limited compared to those for many other common, complex conditions. Indeed, expectations and attitudes about AD susceptibility testing and responses to results disclosure may change dramatically as proven strategies to reduce $\mathrm{AD}$ risk emerge. In addition, results may not generalize to broader segments of the population, given that participants were predominantly of higher socioeconomic status and generally highly motivated to pursue risk information. We also screened out participants who showed moderate to severe psychiatric and/or cognitive difficulties at baseline. Behavioral changes were primarily assessed through self-report and only

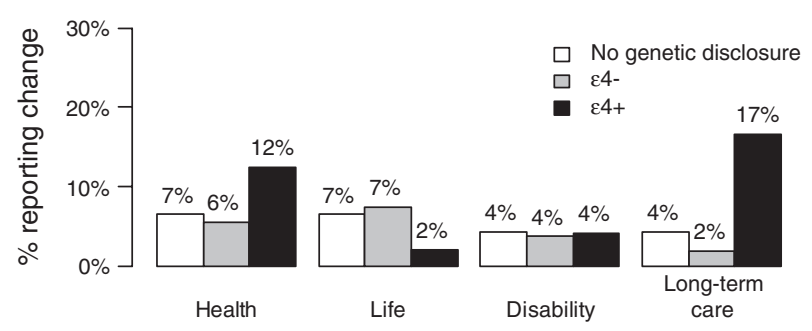

Fig. 3. Proportion of participants in the first REVEAL Study trial reporting insurance change during 12 months following genetic risk disclosure, stratified by randomization status/APOE genotype and insurance domain. APOE, apolipoprotein E; REVEAL, Risk Evaluation and Education for Alzheimer's Disease. up to 1 year following disclosure; future studies should seek more objective measures of these domains, with longer term follow-up. Finally, research presented here was conducted primarily in the United States. There is limited cross-national work in this area, although one survey comparing the beliefs of Italians and Americans about genetic susceptibility testing for AD suggested stronger beliefs among Americans about the likelihood of developing $\mathrm{AD}$, greater $\mathrm{AD}$ knowledge, stronger beliefs that susceptibility testing can help with planning for the future, and greater fears about the possibility of insurance and employment discrimination (51). Such findings suggest that cultural differences in lifestyles, social systems and health policies may impact attitudes toward susceptibility testing.

\section{Future directions}

\section{Alternative service delivery models}

The time-intensive, traditional genetic counseling model will need to be adapted to accommodate the needs of a growing number of patients seeking genetic testing for adult-onset conditions (52). Leaders in the field have called for a model of care emphasizing briefer protocols and use of supplementary educational media $(53,54)$. In this spirit, the second REVEAL trial examined the impact of a condensed clinical risk communication protocol for first-degree relatives of people with $\mathrm{AD}$, as compared to the extended protocol developed in our first trial. The condensed protocol was delivered in fewer sessions and required less face-toface time $($ mean $=33$ vs $76 \mathrm{~min})$ with the study clinician. In addition, participants did not differ by protocol in terms of depression and anxiety symptoms or by rates of risk recall and comprehension at any point in the yearlong follow-up period (55). We are also continuing to address emerging trends in provision of genetic test results with ongoing analyses of the third REVEAL trial, where telephone disclosure of $A P O E$ results was compared to an in-person model. The trial also examined the impact of disclosure of pleiotropic disease risks (i.e. $\mathrm{AD}$ and coronary artery disease) associated with $A P O E$.

\section{Conclusion}

Experts forecast that genetic susceptibility testing for common adult-onset diseases will become much more commonplace in the future, and $\mathrm{AD}$ and $A P O E$ testing provide a fruitful paradigm in which to examine its potential benefits and harms. 


\section{Alzheimer's disease as a model for genetic risk disclosure}

Results indicate that many individuals are interested in genetic testing for non-medical reasons and that provision of test results does not generally result in adverse psychological effects if delivered by trained professionals using appropriate educational approaches. Furthermore, our results suggest that modifications to streamline the genetic counseling process in this context can be made without increasing the likelihood of participant distress or misunderstanding. However, our findings also show numerous challenges associated with the estimation and communication of genetic risk for $\mathrm{AD}$ and they suggest a potential future need to develop policies to address genetic discrimination in LTC insurance. Lessons from the REVEAL Study may be useful to bear in mind as the field of personal genomics continues to expand. However, despite our attempts to keep pace with evolving practices, the rapid pace of scientific discoveries and commercial efforts to market genetic tests is overwhelming our ability to generate a clinical research evidence base to guide practice and policy. Already being provided are all-in-one personal genomic services that include carrier screening, pharmacogenetic tests, and susceptibility testing for scores of health conditions. Understanding and teasing apart reactions to genetic information provided in such a format will undoubtedly prove vexing and may strain the limits of our traditional clinical trials designs. Yet, such research will be critical if we are to responsibly integrate genomic discoveries into both healthcare and society at large.

\section{Acknowledgements}

The authors acknowledge members of the REVEAL Study Group, including teams at Boston University (Clara Chen, Adrienne Cupples, Lindsay Farrer), Case Western Reserve University (Peter Whitehouse and Melissa Barber Butson), Weill Medical College of Cornell University (Norman Relkin), Duke University (Robert Cook-Deegan, Charmaine Royal), Howard University (Thomas Obisesan), and the University of Michigan (Erin Linnenbringer, Wendy Uhlmann). The authors would also like to thank Lindsay Zausmer for her assistance with manuscript preparation. This work was supported by grants from the National Human Genome Research Institute (R01 HG02213 and R01 HG005092) and the National Alzheimer's Association (IIRG-07-58189).

\section{References}

1. Burke W, Psaty BM. Personalized medicine in the era of genomics. JAMA 2007: 298: 1682-1684.

2. Urquidi V, Goodison S. Genomic signatures of breast cancer metastasis. Cytogenet Genome Res 2007: 118: 116-129.

3. Hudson K, Javitt G, Burke W et al. ASHG statement on direct-to-consumer genetic testing in the United States. Am J Hum Genet 2007: 81: 635-637.

4. Offit K. Genomic profiles for disease risk: predictive or premature? JAMA 2008: 299: 1353-1355.
5. Burke W. Clinical validity and clinical utility of genetic tests. Curr Protoc Hum Genet 2009: 60: 9.15.11-19.15.17.

6. Hubbard R, Lewontin RC. Pitfalls of genetic testing. N Engl J Med 1996: 334: 1192-1193.

7. Evans JP. Health care in the age of genetic medicine. JAMA 2007: 298: 2670-2672.

8. Secretary's Advisory Committee on Genetics, Health and Society. A roadmap for the integration of genetics and genomics into health and society. Washington, DC: Department of Health \& Human Services, 2004.

9. Collins FS, Green ED, Guttmacher AE et al. A vision for the future of genomics research. Nature 2003: 422: 835-847.

10. Go VLW, Wong DA, Wang Y et al. Diet and cancer prevention: evidence-based medicine to genomic medicine. J Nutr 2004: 134: 3513S-3516S.

11. Alzheimer's Association 2011. Alzheimer's disease facts and figures. Alzheimers Dement 2011: 7: 208-244.

12. Steinbart EJ, Smith CO, Poorkaj P et al. Impact of DNA testing for early-onset familial Alzheimer disease and frontotemporal dementia. Arch Neurol 2001: 58: 1828-1831.

13. Mihaescu R, Detmar SB, Cornel MC et al. Translational research in genomics of Alzheimer's disease: a review of current practice and future perspectives. J Alzheimers Dis 2010: 20: $967-980$.

14. Bertram L, Lange C, Mullin K et al. Genome-wide association analysis reveals putative Alzheimer's disease susceptibility loci in addition to APOE. Am J Hum Genet 2008: 83: 623-632.

15. Hollingworth $P$, Harold D, Sims R et al. Common variants at ABCA7, MS4A6A/MS4A4E, EPHA1, CD33 and CD2AP are associated with Alzheimer's disease. Nat Genet 2011: 43: 429-435.

16. Farrer LA, Brin MF, Elsas L et al. Statement on use of apolipoprotein E testing for Alzheimer disease. JAMA 1995: 274: $1627-1629$.

17. Relkin NR, Gandy S. Consensus statements on the use of ApoE genotyping in Alzheimer's Disease. Neurol Alert 1996: 14: $58-59$.

18. Post SG, Whitehouse PJ, Binstock RH et al. The clinical introduction of genetic testing for Alzheimer disease. An ethical perspective. JAMA 1997: 277: 832-836.

19. McConnell LM, Koenig BA, Greely HT et al. Genetic testing and Alzheimer disease: has the time come? Nat Med 1998: 4: 757-759.

20. Morris JC. Dementia update 2005. Alzheimer Dis Assoc Disord 2005: 19: 100-117.

21. Roberts JS, Connell CM. Illness representations among firstdegree relatives of people with Alzheimer disease. Alzheimer Dis Assoc Disord 2000: 14: 129-136.

22. Christensen KD, Roberts JS, Uhlmann WR et al. Changes to perceptions of the pros and cons of genetic susceptibility testing after APOE genotyping for Alzheimer disease risk. Genet Med 2011: 13: 409-414.

23. Lautenschlager NT, Cupples LA, Rao VS et al. Risk of dementia among relatives of Alzheimer's disease patients in the MIRAGE study: what is in store for the oldest old? Neurology 1996: 46: 641-650.

24. Farrer LA, Cupples LA, Blackburn S et al. Interrater agreement for diagnosis of Alzheimer's disease: the MIRAGE study. Neurology 1994: 44: 652-656.

25. Farrer LA, Cupples LA, Haines JL et al. Effects of age, sex and ethnicity on the association between apolipoprotein $\mathrm{E}$ genotype and Alzheimer disease: a meta-analysis. JAMA 1997: 278: 1349-1356.

26. Washington HA. Medical apartheid: the dark history of medical experimentation on Black Americans from colonial times to the present. New York, NY: Doubleday, 2006. 


\section{Roberts et al.}

27. Christensen KD, Roberts JS, Royal CDM et al. Incorporating ethnicity into genetic risk assessment for Alzheimer disease: the REVEAL Study experience. Genet Med 2008: 10: 207-214.

28. Roberts JS, Barber M, Brown TM et al. Who seeks genetic susceptibility testing for Alzheimer's disease? Findings from a multisite, randomized clinical trial. Genet Med 2004: 6: 197-203.

29. Esplen MJ, Madlensky L, Aronson M et al. Colorectal cancer survivors undergoing genetic testing for hereditary nonpolyposis colorectal cancer: motivational factors and psychosocial functioning. Clin Genet 2007: 72: 394-401.

30. Hensley Alford S, McBride CM, Reid RJ et al. Participation in genetic testing research varies by social group. Public Health Genomics 2011: 14: 85-93.

31. Roberts JS, LaRusse SA, Katzen $\mathrm{H}$ et al. Reasons for seeking genetic susceptibility testing among first-degree relatives of people with Alzheimer disease. Alzheimer Dis Assoc Disord 2003: 17: 86-93.

32. Woloshin S, Schwartz LM. How can we help people make sense of medical data? Eff Clin Pract 1999: 2: 176-183.

33. Lipkus IM. Numeric, verbal, and visual formats of conveying health risks: suggested best practices and future recommendations. Med Decis Making 2007: 27: 696-713.

34. Roberts JS, Cupples LA, Relkin NR et al. Genetic risk assessment for adult children of people with Alzheimer's disease: the Risk Evaluation and Education for Alzheimer's Disease (REVEAL) Study. J Geriatr Psychiatry Neurol 2005: 18: $250-255$.

35. Eckert SL, Katzen H, Roberts JS et al. Recall of disclosed apolipoprotein E genotype and lifetime risk estimate for Alzheimer's disease: the REVEAL Study. Genet Med 2006: 8: 746-751.

36. LaRusse S, Roberts JS, Marteau TM et al. Genetic susceptibility testing versus family history-based risk assessment: impact on perceived risk of Alzheimer disease. Genet Med 2005: 7: 48-53.

37. Linnenbringer E, Roberts JS, Hiraki S et al. "I know what you told me, but this is what I think:" perceived risk of Alzheimer disease among individuals who accurately recall their geneticsbased risk estimate. Genet Med 2010: 12: 219-227.

38. Beck AT, Epstein N, Brown G et al. An inventory for measuring clinical anxiety: psychometric properties. J Consult Clin Psychol 1988: 56: 893-897.

39. Radloff LS. The CES-D scale: a self-report depression scale for research in the general population. Appl Psychol Meas 1977: 1: 385-401.

40. Horowitz M, Wilner N, Alvarez W. Impact of Event Scale: a measure of subjective stress. Psychosom Med 1979: 41: 209-218.
41. Green RC, Roberts JS, Cupples LA et al. A randomized trial of APOE genotype disclosure for risk of Alzheimer's disease: the REVEAL Study. N Engl J Med 2009: 361: 245-254.

42. Heshka JT, Palleschi C, Howley H et al. A systematic review of perceived risks, psychological and behavioral impacts of genetic testing. Genet Med 2008: 10: 19-32.

43. Meiser B. Psychological impact of genetic testing for cancer susceptibility: an update of the literature. Psychooncology 2005: 14: 1060-1074.

44. Marteau TM, Lerman C. Genetic risk and behavioural change. BMJ 2001: 322: 1056-1059.

45. Marteau T, Senior V, Humphries SE et al. Psychological impact of genetic testing for familial hypercholesterolemia within a previously aware population: a randomized controlled trial. Am J Med Genet A 2004: 128A: 285-293.

46. Phelan JC, Yang LH, Cruz-Rojas R. Effects of attributing serious mental illnesses to genetic causes on orientations to treatment. Psychiatr Serv 2006: 57: 382-387.

47. Senior V, Marteau TM. Causal attributions for raised cholesterol and perceptions of effective risk-reduction: self-regulation strategies for an increased risk of coronary heart disease. Psychol Health 2007: 22: 699-717.

48. Chao S, Roberts JS, Marteau TM et al. Health behavior changes after genetic risk assessment for Alzheimer disease: the REVEAL Study. Alzheimer Dis Assoc Disord 2008: 22: 94-97.

49. Zick CD, Mathews CJ, Roberts JS et al. Genetic testing for Alzheimer's disease and its impact on insurance purchasing behavior. Health Aff 2005: 24: 483-490.

50. Taylor DH Jr, Cook-Deegan RM, Hiraki S et al. Genetic testing for Alzheimer's and long-term care insurance. Health Aff 2010: 29: 102-108.

51. Binetti G, Benussi L, Roberts $\mathrm{S}$ et al. Areas of intervention for genetic counselling of dementia: cross-cultural comparison between Italians and Americans. Patient Educ Couns 2006: 64: 285-293.

52. Resta RG. Defining and redefining the scope and goals of genetic counseling. Am J Med Genet 2006: 142: 269-275.

53. Guttmacher AE. Human genetics on the web. Annu Rev Genomics Hum Genet 2001: 2: 213-233.

54. Guttmacher AE, Jenkins J, Uhlmann WR. Genomic medicine: who will practice it? A call to open arms. Am J Med Genet 2001: 106: 216-222.

55. Green RC, Roberts JS, Chen $\mathrm{C}$ et al. Comparing the impact of a condensed vs extended protocol for disclosure of APOE to relatives of patients with AD: The REVEAL Study. Alzheimers Dement 2007: 3: S184. 